\title{
SINDROME DE RAEDER CAUSADA POR ANEURISMA DISSECANTE DA CARÓTIDA
}

\author{
FERNANDO GUILHON HENRIQUES * - DOROTY ANTONIA LOPES TRINTA**
}

\begin{abstract}
RESUMO - Os autores descrevem um caso de sindrome paratrigeminal de Raeder causada por aneurisma dissecante da carótida interna e tecem comentários scbre aspectos do diagnóstico.
\end{abstract}

Rueder's syndrome caused by a dissecant carotid aneurysm.

SUMMARY - The authors report a case of Raeder's paratrigeminal syndrome and make some comments about the diagnosis: a dissecant aneurysm of internal carotia artery.

Em 1924 Raeder publicou um trabalho com a descrição de cinco casos semethantes de pacientes que apresentavam cefaléia unilateral associada a síndrome de Horner ipsilateral ao que designou de "sindrome paratrigeminal" por supor que a patologia causadora da sindrome estava localizada próxima do nervo trigêmeo ocasionando o fenômeno doloroso. Em alguns de seus pacientes além da dor e da síndrome oculossimpática havia também comprometimento de nervos cranianos parasselares. Recentemente tivemos a oportunidade de observar um caso de hemicrânia associada a sindrome de Horner ipsilateral causada por aneurisma dissecante da carótida interna que configura o tipo II da sindrome de Raeder, conforme sugestão de classificação de Boniuk e Schelezinger 1, e que pelo inusitado de sua ocorrência julgamos oportuno divulgar.

\section{OBSERVAC̄AO}

O.F.M., 43 anos, feminina, branca, casada, doméstica, registro HBDF-029645. Foi internada na Unidade de Neurologia do HBDF no dia 21-10-86 dizendo que havia cerca de 10 dias fora acometida de cefaléia aguda, de forte intensidade, localizada na regiāo frontal đireita, de caráter pulsátil e irradiada para a nuca e região ocular do mesmo lado. Após cerca de 18 horas essa dor foi acompanhada de parestesias na metade direita da cabeça e instalou-se diminuição da fenda palpebral ipsilateral, sendo notada então hipertensầ arteriai (PA sistólica de $200 \mathrm{mmHg}$ ). Foi medicada com analgésicos e observou alguma melhora cio quadro doloroso. Três dias depois, com o recrudescimento da dor, de caráter pulsátil, surgiram vâmitos pós-prandiais e a paciente observou obstrução da narina direita. Relatou antecedente de enxaqueca, atipica, e distúrbios emocionais frequientes. Ao exame observamos exoftalmia bilateral, estreitamento da fenda palpebral direita, miose à direita, discreta hiperemia conjuntival desse lado. Referia obstrução nasal à direita. Não encontramos sinais objetivos de acometimento do nervo trigêmeo nem de qualquer outro nervo craniano. Năo havia distúrbios da sudorese na face. Durante a internação permaneceu queixando-se de cefalé:a que variava em sua intensidade, bem como da obstruçăo nasal à direita, apesar do uso de vários medicamentos (derivados da ergotamina, antidepressivos, benzodiazopinicos, analgésicos, descongestionantes nasaís) e só obteve algum alívio da cefaléia por ocasião da alta, quando sua pressāo arterial se normalizou. Hemograma, glicemia, dosagem de eletrólitos, uréia e creatinina, $\mathbf{R x}$ do tórax, exame sumário da urina e $\mathbf{R x}$ do crânio com incidências em AP e perfil e para visualização dos rochedos, foram todos normais. Angiografia carotídea direita revelou aneurisma dissecante da carótida interna à direita (Fig: 1).

* Professor Adjunto da Universidade de Brasília, Neurologista; ** Médica Residente da Unidade de Neurologia do Hospital de Base do Distrito Federal (HBDF).

Depariamento de Medicina Especializada - Faculdade de Ciências da Saúde $\rightarrow$ Universidade de Brasília - 70910 Brasítia DF - Brasil. 

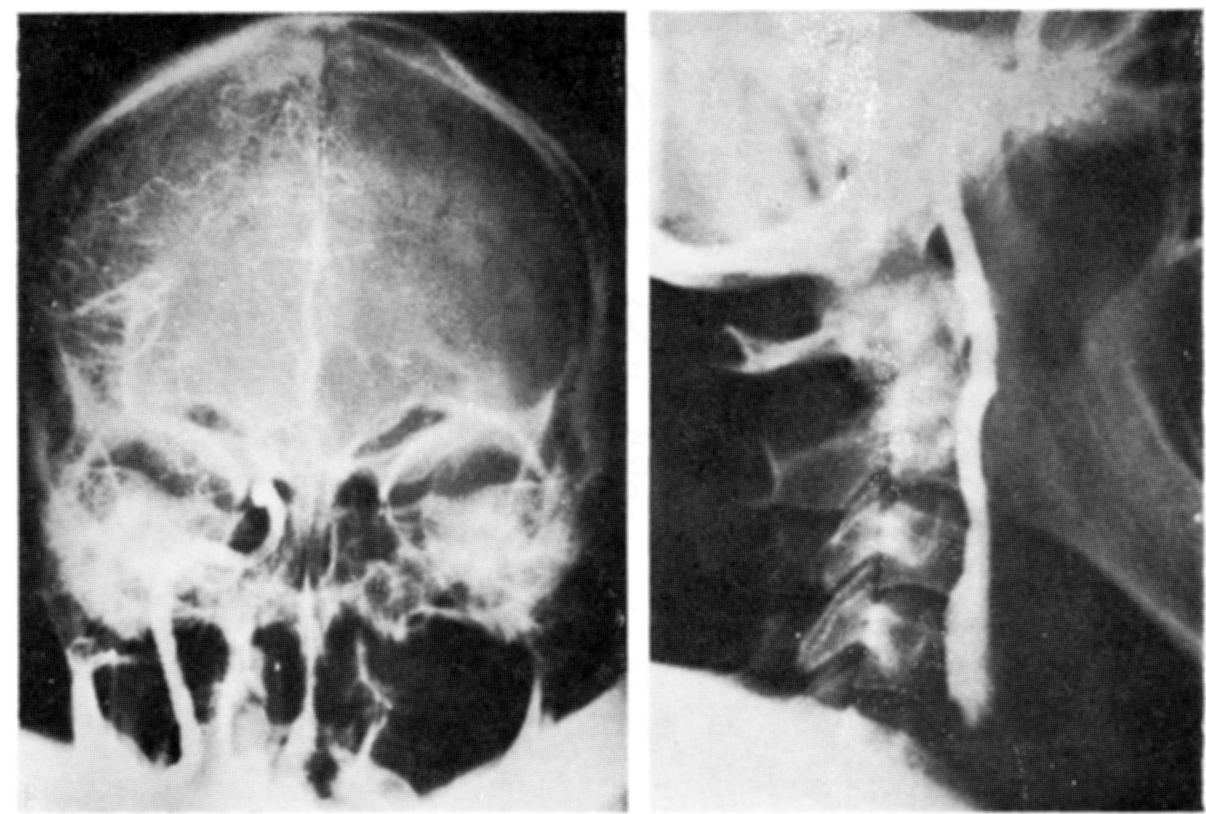

Fig. 1 - Caso O.F.M.: angiografia carotídea direita. À esquerda, visão frontal observando-se irregularidade da parede arterial dix carótida. À dineita, detalhe da lesão arterial.

\section{COMENTARIOS}

Em 1962 Boniuk e Schelezinger1 estudando 9 casos de sindrome de Raeder, propuseram a divisão desta sindrome em dois grupos: com e sem comprometimento associade de nervos cranianos parasselares, e incluem seus casos neste último grupo. $O$ nosso estaria, por esse critério, classificado também no grupo daqueles sem acometimento de outros nervos cranianos. Os autores em geral estão de acordo em que a síndrome de Horner verificada nesses casos é devida ao acometimento do simpático ocular ao nivel da carótida interna. A via simpática é ipsilateral e possui três neurônios: o primeiro, diencefálico, cujo axônio desce passando pelo mesencéfalo, ponte e bulbo, faz sinapse na coluna intermédio-lateral da medula torácica superior; os neurônios de segunda ordem saem com as três primeiras raízes torácicas, passam através do gânglio estrelado e seguem o tronco simpático para fazerem sinapseses no gânglio cervical superior; as fibras de terceira ordem acompanham a artéria carótida interna até o crânio e então passam através do rochedo para entrarem na cavidade craniana onde acompanham a divisão oftálmica do nervo trigêmeo e seus ramos ciliares até atingirem as fibras dilatadoras da pupila na íris (Fig. 2) 6 .

A inervação das glândulas sudoriparas da face, acredita-se, segue caminho diferente pela carótida externa e ramos faciais. Assim, a presença ou ausência de distúrbio da sudorese na face autorizaria localizar a lesăo antes do terceiro neurônio da via simpática, ou neste, ao nível da carótida interna 1 . A diminuição da fenda palpebral e a miose, em nossa paciente, configuram o comprometimento parcial do simpático ocular ao nivel do terceiro neurônio, isto é, na carótida interna.

Chamou-nos atençāo a obstruçāo nasal referida pela paciente, a qual não costuma fazer parte da sindrome de Horner, mas que poderia dever-se a fenômeno de vasodilataçāo localizada na mucosa do nariz, não visivel na hemiface, apenas esboçado na conjuntiva ocular, e do ponto de vista fisiopatológico explicável pelo acometimento simpático. Tal achado motivou a especulação diagnóstica diferencial com a cefaléia em salvas, de Horton (cluster headache), em que a obstrução nasal não é rara e que muitas vezes se acompanha da sindrome de Horner 5.

A dor que nossa paciente apresentava, bem poderia ser uma simpatalgia ou carotidinia, provocada pela lesão da parede arterial, mais do que uma trigeminalgia, desde que não havia sinais objetivos de acometimento do trigêmeo. 


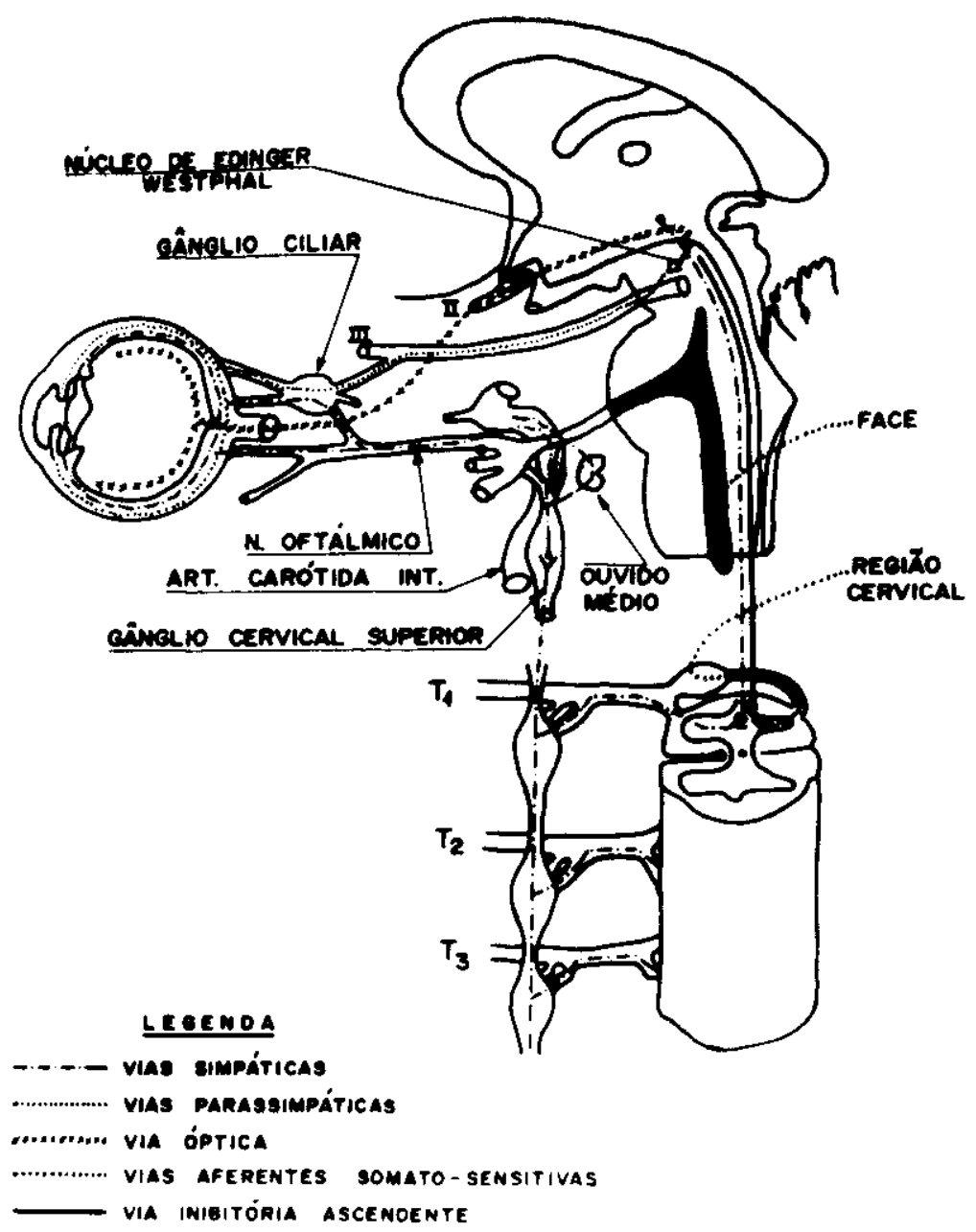

Fig. z Via simpatica ocular.

Vários casos 2,5 têm sido descritos, de aneurisma dissecante da carótida prodızindo a sindrome de Raeder, e na literatura nacional este parece ser o primeiro, fato que corrobora a opiniāo de Cohen et al. 3 e Mokri et al. 5 para os quais em cefaléias em salva persistentes as patologias vasculares devem ser admitidas e procuradas por meio de investigação angiográfica dos vasos extracranianos.

\section{REFERENCIAS}

1. Boniuk M, Schelezinger NS - Raeder's paratrjgeminal syndrome. Am $J$ Ophthalm $54: 1074,1962$.

2. Davis RH, Daroff RB, Hoyt FW - Hemicrania, oculosympathetic paresis and subcranial carctid aneurysm: Reader's paratrigeminal syndrome. J Neurosurg 29:94, 1968.

3. Cohen DZ, Zakov AN, Salnga VD, Dohn DF - Raeder's paratrigeminal syndrome. Am J Ophthalm 79:1044, 1975.

4. West TET, Davies RJ, Kelly RE - Horner's syndrome and headache due to carotid artery disease. $\mathrm{Br}$ Med $\mathrm{J} 1: 818,1976$.

5. Mokri B, Sundt TMJr, Houser OW - Spontaneous internal carotid dissection, hemicrania and Horner's syndrome. Arch Neurol 36:677, 1979.

6. Henriques FG, Leăo IA - Reflexo cillio-espinhal no homem. Arq Neuro-Psiquíat (Säo Paulo) 34:258, 1976. 